Test of CAP88-PC's Predicted Concentrations of Tritium in

S-R. Peterson

July 2004

Accepted by Health Physics, The Radiation Safety Journal 


\section{Disclaimer}

This document was prepared as an account of work sponsored by an agency of the United States Government. Neither the United States Government nor the University of California nor any of their employees, makes any warranty, express or implied, or assumes any legal liability or responsibility for the accuracy, completeness, or usefulness of any information, apparatus, product, or process disclosed, or represents that its use would not infringe privately owned rights. Reference herein to any specific commercial product, process, or service by trade name, trademark, manufacturer, or otherwise, does not necessarily constitute or imply its endorsement, recommendation, or favoring by the United States Government or the University of California. The views and opinions of authors expressed herein do not necessarily state or reflect those of the United States Government or the University of California, and shall not be used for advertising or product endorsement purposes.

\section{Auspices Statement}

This work was performed under the auspices of the U.S. Department of Energy by University of California, Lawrence Livermore National Laboratory under Contract W7405-Eng-48. 
UCRL-JRNL-201833

\title{
Test of CAP88-PC's Predicted Concentrations of Tritium in Air at Lawrence Livermore National Laboratory
}

\begin{abstract}
S-R. Peterson ${ }^{*}$
ABSTRACT - Based on annual tritium release rates from the five sources of tritium at Lawrence Livermore National Laboratory and the Tritium Research Laboratory at Sandia National Laboratory, the regulatory dispersion and dose model, CAP88-PC, was used to predict tritium concentrations in air at perimeter and offsite air surveillance monitoring locations for 1986 through 2001. These predictions were compared with mean annual measured concentrations, based on biweekly sampling. Deterministic predictions were compared with deterministic observations using predicted-to-observed ratios. In addition, the uncertainty on observations and predictions was assessed: when the uncertainty bounds of the observations overlapped with the uncertainty bounds of the predictions, the predictions were assumed to agree with the observations with high probability. Deterministically, $54 \%$ of all predictions were higher than the observations, and $96 \%$ fell within a factor of three. Accounting for uncertainty, $75 \%$ of all predictions agreed with the observations; $87 \%$ of the predictions either matched or exceeded the observations. Predictions equaled or exceeded observations at those sampling locations towards which the wind blows most frequently, except those in the hills. Under-predictions were seen at locations towards which the wind blows infrequently when released tritium was from elevated sources. When a high fraction of tritium was from area (diffuse) sources, predictions matched observations.
\end{abstract}




\section{INTRODUCTION}

CAP88-PC (Parks 1992, 1997) is a model approved by the Environmental Protection Agency (EPA) for determining compliance with 40 CFR Part 61, Subpart H (National Emission Standards for Emissions of Radionuclides Other Than Radon from Department of Energy Facilities) (USEPA 1989). Since 1997, Lawrence Livermore National Laboratory (LLNL) has compared the tritium concentrations in air predicted by CAP88-PC with concentrations measured at seven perimeter, one offsite and four onsite locations. These results have been published in the LLNL annual National Emission Standards For Hazardous Air Pollutants (NESHAPs) reports (e.g., Harrach et al. 2002). CAP88-PC, however, had not been tested against observed concentrations of tritium in air at several offsite locations.

Model predictions can be compared with observations with or without accounting for uncertainties. When predictions and observations are treated as single best-estimate values, $\mathrm{P} / \mathrm{O}$ ratios can be compared from different model tests. When uncertainties on the predictions and observations are estimated, if the uncertainties overlap, then the prediction is, with high probability, the same as the observation.

In this paper, observed air tritium concentrations for the seven LLNL perimeter locations (Fig. 1 and Table 1a) and six above-detection limit, offsite locations (Fig. 2 and Table 1b) for the years 1986 through 2001 are compared, both deterministically by $\mathrm{P} / \mathrm{O}$ ratios and probabilistically by considering overlapping uncertainties, with predictions of CAP88-PC using source terms from LLNL facilities and the Tritium Research Laboratory (TRL) at Sandia National Laboratory (SNL). Sampling locations ALTA and $\mathrm{AMON}^{+}$are the farthest locations from any LLNL or SNL tritium source (about six to eight kilometers) with measurable air tritium concentrations.

Because CAP88-PC is a regulatory tool, one might hope that most air concentrations would be over-predicted. In CAP88-PC, a default roughness length of $0.01 \mathrm{~m}$ (for lawn grass and open water) should ensure that air concentrations will be overestimated more than two or three kilometers downwind of the elevated source, because the plume will not be as dispersed as much as if a greater, more realistic roughness length were used. In addition, the fact that meteorological data collected from $10 \mathrm{~m}$ is used in the preparation of the CAP88-PC wind files may contribute towards over-prediction of air concentrations when the source is elevated and plume rise is not important. When a wind file of $10 \mathrm{~m}$ data is applied to an elevated stack, such as at LLNL's Tritium Facility (TF) (in operation since 1953) or SNL's TRL (operational 1979-1995), predicted air concentrations may be higher than those measured because the actual wind speeds at stack height $(30 \mathrm{~m})$ are higher than those at $10 \mathrm{~m}$, and the plume will be more diluted. This effect may be counteracted by the fact that light winds (at $10 \mathrm{~m}$ ) will result in greater plume rise, and therefore predicted air concentrations will be lowered, at least close to the source.

\footnotetext{
${ }^{\dagger}$ AMON replaced ALTA as sampling location in March 1998.
} 
When 10-m wind file data are applied to near ground-level sources, the predicted air concentrations should be lower than initially observed when the release is confined to the layer near the ground that experiences a lower wind speed. Any under-prediction will decrease downwind as the center of mass of the plume rises and the wind speed that it experiences increases and comes closer to the 10-m value. On the other hand, the use of CAP88-PC's roughness length of $0.01 \mathrm{~m}$ should cause predicted air concentrations from ground level releases to be higher than measured because a small roughness length implies little vertical spreading with resulting high concentrations from ground-level releases. Furthermore, CAP88-PC has only a single set of stability classes that represents vertical stability, and some overprediction in stable conditions may be expected because the real plume undergoes significant lateral spreading that isn't accounted for by vertical stability alone.

The basic conservatism of CAP88-PC's dispersion model arises from the assumptions described above, because, in general, when a Gaussian plume model has the proper parameters, annual average air concentrations over flat terrain can only be predicted within a factor of two to four, with accuracy decreasing as complexity of meteorological and terrain conditions increases (Miller and Hively 1987). From previous testing of CAP88-PC with LLNL air tritium data (Harrach et al. 2002) and with data from the Savannah River Site (Simpkins and Hamby 1997), expectations of over-prediction have been confirmed.

\section{METHODS}

\section{Air tritium observations}

$$
\text { Sampling and analysis }
$$

Biweekly measurements of tritium in air have been collected by LLNL at many locations since 1973. A pump pulls air across silica gel, which adsorbs the water moisture from the air. In the laboratory, adsorbed moisture is extracted from the silica gel by freeze-drying, and the tritium activity in the extracted water is counted by liquid scintillation methods. Concentrations of tritium in air $\left(\mathrm{pCi} / \mathrm{m}^{3}\right)$ are calculated by multiplying the tritium concentration in $\mathrm{pCi} / \mathrm{mL}$ measured by scintillation counting times the mass of water adsorbed (wet weight silica gel minus dry weight silica gel) in $\mathrm{mL}$ to get the total tritium in the sample, which is then divided by the volume of air passed through the gel during the sampling period. Air volumes were calculated up until 1999 by averaging rotameter readings at the start and end of sampling to obtain the average flow rate, which was then multiplied by the elapsed sampling time. In May 1999, flow meters were installed on all samplers; these flow meters measure the actual flow for the sampling period, thus eliminating the need to estimate the total volume of air passed through the sampler.

Until 2001, LLNL reported concentrations of air tritium based on direct measurements of tritium in water extracted from silica gel, as had been done since 
the start of the air tritium network. In 2001, because of recently published insights into the properties of silica gel, LLNL developed a correction factor that accounts for structural water bound in the silica gel (Guthrie et al. 2002). This latent water effectively dilutes the tritium in air moisture adsorbed on the silica gel. The correction factor varies with each sample, because it depends upon the mass of water collected compared with the total mass of dry silica gel. The more water collected, the smaller the correction factor.

The correction factor for 2001 was developed based on 2.0 to $5.0 \mathrm{~mm}$ TellTale ${ }^{\circledR}$ Grade 48 indicating silica gel beads (Grace Davison, Columbia, MD 21044). Prior to the use of beads, an amorphous silica gel had been used, and other types or batches of gel have been used over the years. The average correction factor \pm standard deviation for the silica gel beads is $1.6 \pm 0.18$; on average, the corrected concentration is 1.6 times higher than the uncorrected concentration. On an individual basis, most correction factors fall between 1.2 and 1.9. To correct air tritium concentrations individually prior to 2001 is impossible, because the dry weight of the silica gel was not measured until the need for a correction factor was recognized. In addition, the range of average correction factors for other types of silica gel is unknown. A few numbers ${ }^{\ddagger}$ published in the literature indicate that the fraction of latent water in other silica gels is similar to that in the beads and perhaps might even indicate the necessity for a higher correction factor. However, without actual measurements, even the average correction factor for historic silica gel cannot be known with any accuracy. Nevertheless, a factor of $1.6 \pm 0.18$ has been applied to all the observations from 1986 through 2000.

\section{Preparation of observed data for model testing}

Air tritium data were selected to test CAP88-PC for a particular year if they met the following criteria:

- $75 \%$ or more of the samples in a year at one location were collected.

- More than $50 \%$ of potential samples were above the lower limit of detection.

Out of 195 potential annual sets of data, 159 met the above criteria. From the selected data, biweekly concentrations for each year were plotted to look for spurious peaks (both high and low) that would be impossible for CAP88-PC to predict. Monitors located in similar wind directions (see Fig. 1 and Fig. 2) were plotted together (ALTA or AMON, COW, ZON7, and VIS to the northeast; FIRE, LCCY, MESQ and MET to the west; CAFÉ, POOL, SALV, VET and XRDS to the south). Many times the air concentrations in the selected groupings tracked together perfectly. Other times two might rise and two might fall on any one sampling date. However, only when the air concentration at one location was obviously counter to the others was the concentration rejected, because CAP88-PC would not be able to account for such an anomaly. Some of these spurious peaks were outliers

\footnotetext{
* Percent water from references cited in Guthrie et al. 2002: LLNL baked silica gel,
} 5.12; other gels, 5.3, 5.8, 5.9, and 6.3. 
acknowledged in the Site Annual Environmental Reports of 1986 and 1987 (Holland et al. 1987; Holland and Brekke 1988). Others may have been due to temporary, localized sources "seen" only by one monitor. Still others were extremely low real measurements. Negative concentrations were all discarded.

Means of the biweekly data, with a few highly improbable numbers removed, for each year at each selected location were calculated and multiplied by the silica gel correction factor as needed. Estimated background of cosmogenic and bomb fallout tritium was subtracted from the mean values.

Four sources of uncertainty on the observations were identified and quantified. The first is the analytical, or counting, uncertainty on each sample. The counting error is the uncertainty on the estimated concentration of the sample and varies depending upon the concentration, how long the sample was counted, and other factors. The uncertainty on the annual mean cannot be known precisely. To assess the association between percent errors and concentrations over time, for each year's data set, all percent errors were graphed against the concentrations. There is a reasonably consistent correlation between concentrations and percent errors for 1986 through 1991, 1992 through 1996, and 1997 through 2001. From these groupings, average percent errors were calculated for small ranges in concentrations. In this manner, an average percent error was derived for each mean annual air concentration for each location.

The appropriate factor with which to correct for dilution of tritium in air moisture by latent water in silica gel is a second source of uncertainty. Obviously, if the correction factor were reduced, predictions will be higher relative to the lowered observations; the converse is also true. Given known measurements of percent latent water in silica gel, a correction factor of 1.6 seems reasonable. However, even if the correction factor of 1.6 does apply on average to all years, the use of a single factor introduces some uncertainty for individual results. In the absence of any evidence that silica gels might have distinctly different fractions of latent water, the uncertainty (11\% from the standard deviation on 700 samples) on the correction factor of 1.6 has been applied to all observations (except for 2001, when each sample was corrected individually) as being potentially correct for all types of silica gel.

A third uncertainty on concentrations of tritium in air arises from uncertainty in the average flow rate. Since April 1999 when flow meters were first used for the air tritium network, the hourly average flow rate has varied by plus or minus $14 \%$. This uncertainty has been applied to the air concentrations that were calculated based on rotameter readings. In addition, a small LLNL study (unpublished) compared biweekly air volumes measured by flow meter and by rotameter from April 1999 to December 2002 for all LLNL air tritium samplers. The total flows obtained from averaging the flow rate at the start of the sampling period with the flow rate at the end of the sampling period using rotameter readings and then accounting for time elapsed were consistently $5 \%$ higher than the total flows measured by the flow meter. These results indicate, that, on average, concentrations obtained prior to 1999 using the rotameters were 5\% lower than in later years, when 
the flow meter data were used. However, the concentrations were not adjusted and these uncertainties were not taken into account quantitatively because they were so small.

Background tritium concentrations, the fourth source of uncertainty, were estimated using tritium in precipitation data obtained from the International Atomic Energy's Global Network of Isotopes in Precipitation (IAEA/WHO 2000). Data from Ottawa (Canada) for 1953 to 1986, Portland (Oregon) for 1963 to 2000, and Santa Maria and Menlo Park (California) for 1963 to 1974 were used to estimate background ${ }^{\S}$. Tritium concentrations from bomb fallout and cosmogenic sources is higher at higher latitudes and away from oceans, but only Ottawa has a set of data going back to 1953. The relative concentrations between Ottawa, Portland, and the two California locations are reasonably constant. It was assumed that California background data from 1963 through 1973 would represent Livermore, and the relationship between the California locations and Portland would be used to estimate Livermore background concentrations for the years of this test. This estimate was then compared with concentrations in California wines sampled as part of LLNL's monitoring program. Uncertainty was adjusted to span the wine concentrations and have an upper limit at the concentrations in precipitation at Portland.

Tritium background concentrations had a negligible effect on observed concentrations in most cases; at the most extreme, in recent years when LLNL's contributions to ambient air tritium were low, the estimated mean background concentrations were only about 6-7\% of the observed air concentrations. Nevertheless, it is important to demonstrate that the air tritium samplers cannot distinguish between concentrations of LLNL tritium and concentrations of bomb fallout and cosmogenic tritium. Furthermore there is considerable uncertainty associated with the estimate of background tritium concentrations that should be added into the overall uncertainty on the observations. Predictions of CAP88-PC obviously only account for tritium released as part of operations.

Observed annual mean concentrations of HTO in air $\left(\mathrm{pCi} \mathrm{m}^{-3}\right)$ for all years and locations of the test are shown in Table 1, as well as estimates of background air concentrations and uncertainty.

\section{Predictions}

The input data needed by CAP88-PC to calculate concentrations of tritium in air are the source term $\left(\mathrm{Ci} \mathrm{y}^{-1}\right)$, stack height (or height of area release), stack diameter (or area), exit velocity $\left(\mathrm{m} \mathrm{s}^{-1}\right)$, distances from the source to the receptor (the air tritium sampler), and site-specific wind file.

$\$$ * R.M. Brown (Atomic Energy of Canada Limited) and Robert Michel (U.S. Geological Survey, Menlo Park) advised that after 1973 in Menlo Park and 1986 in Ottawa, local anthropogenic tritium is being measured in precipitation and therefore these locations no longer demonstrate background tritium concentrations. 
All predictions were calculated using source terms (Table 2) published in the LLNL Site Environmental or NESHAPs Report with the exception of the Container Storage Area (CSA). This source, for the years 1986 until reporting began in 1993, was estimated as $2 \%$ of the annual HTO releases from the TF. This percentage is the observed relationship between the CSA diffuse source term and the TF HTO source terms during recent years when only tritium directly associated with the TF was stored in the CSA. No uncertainty in the reported source terms was assumed. Only estimated releases of tritiated water (HTO) are shown or were modeled. Both the TF and the TRL released quantities of tritiated hydrogen gas (HT), which occasionally exceeded the amount of HTO released. However, HT is relatively inert in the environment and should not be modeled as if it were a release of HTO. The year 1986 was chosen as the first year to test CAP88-PC, because that was the first year that release rates at LLNL were published as HT or HTO in the Site Annual Environmental Report (Holland et al. 1987).

Stack data for the various LLNL sources (Table 3) were obtained from published reports, as well as letters and memoranda. Data were obtained similarly for the TRL at SNL, directly to the south of LLNL. Distances and their bearings from source to receptor were determined using the Global Positioning System (GPS). The locations of the sources are shown in Fig. 1 and Fig. 2, along with the locations of the air tritium monitors. The wind file used for all years was a five-year average based on hourly data obtained from the LLNL meteorological tower for 1997 through 2001.

For each source, the dilution factor $\left(\square / \mathrm{Q}\right.$; units of $\left.\mathrm{s} \mathrm{m}^{-3}\right)$ at each tritium monitor was predicted for both the sector in which the monitor lay and the closest adjacent sector. Given that CAP88-PC is a sector-averaged model, a receptor can lie very close to an adjacent sector with a very different $\square / Q$. Thus a weighted $\square / Q$ was calculated for the exact position of the monitor in a sector relative to the closest adjacent sector. This weighted $\mathrm{\square} / \mathrm{Q}$ was multiplied by the source term for each year of the test to obtain the predicted concentration of tritium in air. Both the XRDS_X and the XRDS_C locations were very sensitive to being at the edge of sectors. Locations COW_X and COW_C were also sensitive, but for all other locations the weighting of $\square / \bar{Q}$ made at most a $10 \%$ difference. Assessing the weighted $\square / \mathrm{Q}$ reduced some potential uncertainty on the predictions.

Five sources of uncertainty in predictions were identified. One source of uncertainty is that CAP88-PC does not account for HTO in the environment from HT released to the atmosphere, although HTO adsorbed by silica gel must include the contribution from HT that has been converted to HTO in the soil and emitted to the atmosphere. For this analysis, only releases of HTO have been modeled, because the contribution of HT to HTO concentrations in air and to dose is minor, but the uncertainty due to this assumption must be recognized. Many factors affect the rate at which HT is converted to HTO, but conversion proceeds efficiently as long as the soil is not saturated or too dry (less than $3 \%$ water by volume; Bunnenberg et al. 1986). Davis and Bickel (2000) recommend a ratio (HTO activity per L air moisture divided by HT activity per $\mathrm{m}^{3}$ air) of 4 to predict a realistic concentration of tritium in 
air moisture from a known (or predicted) concentration of HT in air volume, but how well this experimental ratio applies to LLNL is unknown. Over the 16 years of this test of CAP88-PC, HT contributed 45\% of all tritium released. In 1988, HT from the TF and the TRL contributed the highest fraction of total tritium released $(52 \%)$. If one assumes that the HTO and HT in air at a sampler are in the same proportion as released (which of course will not be true at any location given the numerous sources), one would expect $4.2 \%$ of the measured HTO in 1988 to have come from released HT, based on the conversion factor of 4 . Whatever the assumptions, the contribution of HT to the measured HTO for other years, the contribution will be even less ${ }^{\square}$. The trend, if HT were accounted for, would be to for the predictions to be slightly higher.

A second potential major source of uncertainty is the choice of release parameter values. Exit velocities are only measured infrequently and may change over the years. The exit velocities that were chosen as input to CAP88-PC were correlated with the dates of memos and reports of calibration; an attempt was made to match the exit velocity to the year of release. Choice of exit velocity will impact each receptor differently. For example, for the TF, when the $\mathrm{C} / \mathrm{Q}$ obtained from the lowest reported exit velocity is compared with the $\square / Q$ obtained from the highest reported exit velocity (Table 3), the difference in predictions ranges from a low of about $2 \%$ more for locations to the northeast or east northeast to as much as $20 \%$ more for locations to the west. These represent extremes, and expected annual uncertainty should be much less. Reported exit velocities for the Insulating Core Transformer (ICT) and the Rotating Target Neutron Source (RTNS) were quite variable, but fortunately the magnitude of potential differences had nearly an undetectable effect on the results of the model test because of the relatively small amounts of tritium released from each source (Table 2).

The uncertainty in the source term is extremely important, although for this test it has been assumed that there is no uncertainty on the published release rates. Counting uncertainty on the tritium extracted from the molecular sieves (TF) or bubblers (TRL) is fortunately low, at least in the earlier years of the test, because of the relatively high concentrations collected. The RTNS stack apparently was sampled using silica gel, which means that actual releases will be higher than reported because of the correction factor for latent water in the silica gel. Again, it is fortunate for this test that the releases from the RTNS were relatively very small. Records of releases since 1986 are good, but, because CAP88-PC uses mean annual wind data, if the releases from facilities are not continuous (as they may not be from the facilities with stacks), CAP88-PC is at a disadvantage. Release rates during operations can vary quite a bit between sampling periods. These releases resemble puff releases more than continuous releases, and CAP88-PC cannot be expected to predict the air concentrations from a puff release; if the puffs average out over the

$\square$ The fractions of total tritium released from the LLNL and Sandia Tritium Facilities that were HT were 0.30 (1986), 0.45 (1987), 0.52 (1988), 0.39 (1989), 0.41 (1990), 0.34 (1991), 0.46 (1992), 0.41 (1993), 0.28 (1994), 0.18 (1995), 0.16 (1996), 0.10 (1997), 0.21 (1998), 0.23 (1999), 0.098 (2000), and 0.075 (2001). 
year, as is probable, particularly in recent years, then the uncertainty on CAP88-PC's predictions is not of concern.

Choice of wind file is the fourth potential source of uncertainty. To see the effect of using a 5-year annual wind input instead annual input, the $\mathrm{C} / \mathrm{Q}$ was calculated for each receptor for each source for each wind file (1997-2001 and the 5year average). The $\mathrm{Q} / \mathrm{Q}$ for each annual result was divided by the $\mathrm{Q} / \mathrm{Q}$ resulting from the 5-year wind file, and the five ratios were then averaged for each sourcereceptor combination. Due to CAP88-PC's apparent extreme sensitivity to mean wind speed in each stability class, there are biases in some of the results, i.e., the mean does not average to one. The higher the effective release height, the greater the bias for stack releases (annual $\square / \mathrm{Q}$ greater than the 5-year average); for ground sources, the bias is reversed (annual $\square / Q$ less than the 5-year average). To correct for the observed differences between the annual wind files and the 5-year wind file, the deterministic predictions have been multiplied by the mean of the annual/5-year ratios; the uncertainty on the predictions is the same as the uncertainty on these ratios.

A fifth source of uncertainty is the location of an air sampler relative to the source. Although current receptor locations were located using GPS, the earlier locations cannot be placed accurately because exact locations are unknown. Another problem arises because locations were also changed during the year while results are treated as annual averages. This lack of agreement in space and time will obscure differences with uncertainty that was not quantified here.

\section{RESULTS}

A common and easy way to compare predictions with observations is by the predicted-to-observed $(\mathrm{P} / \mathrm{O})$ ratio. This ratio is a comparison of deterministic predictions with deterministic observations, and uncertainty is not addressed. A $\mathrm{P} / \mathrm{O}$ ratio of 1 means that the predicted air concentration equals the observed air concentration. $\mathrm{P} / \mathrm{O}$ ratios are shown in Table 4 for each location and each year. Results between years and between locations are quite variable, but the overall mean $\mathrm{P} / \mathrm{O}$ ratio is 1.1.

In Table 5, the $\mathrm{P} / \mathrm{O}$ ratios are analyzed according to how they are distributed around a $\mathrm{P} / \mathrm{O}$ ratio of 1.0. The first analysis in Table 5 shows the distributions of the complete data set. $80 \%$ of the $\mathrm{P} / \mathrm{O}$ ratios fall within a factor of $2,96 \%$ fall within a factor of 3 , and $54 \%$ are greater than 1.0. The other analyses shown in Table 5 are of subsets of the entire data set.

CAP88-PC tends to overestimate the relatively close perimeter locations compared with the relatively distant offsite locations. In addition, a difference in results is seen when locations are separated by wind direction and consequently wind frequency and stability class. In the 5-year wind file used for all years, the wind blows to the east, east-northeast, northeast, north-north east and north $47 \%$ of 
the time. Wind blows to the west-southwest, southwest, south-southwest, south, south-southeast and southeast $25 \%$ of the time, and wind blows to the west, westnorthwest, northwest, and north-northwest $14 \%$ of the time. The sampling locations can be loosely grouped into these three categories, called NE, S, and W here for convenience, as was done when the observations were examined for improbable data. The directions mentioned predominate, but with so many source terms, wind from different directions can impact the receptors, particularly for those locations along the southern edge of the site and offsite. Most air concentrations in the direction of the prevailing winds (towards the northeast) are overestimated. When the wind is to the $\mathrm{S}$ or $\mathrm{W}$, less than half of the predictions are greater than the observations, although most fall within a factor of three. (Compare locations in Figs. 1 and 2 with their $\mathrm{P} / \mathrm{O}$ ratios in Table 4.) Predicted-to-observed ratios for recent years $(1993-2001)$ are also better than those for earlier years (1986 - 1992). Seventyone percent of $\mathrm{P} / \mathrm{O}$ ratios for the recent years are above 1.0.

Although the predicted air concentrations have been compared above with the observed concentrations as if both sets of values were known precisely, the uncertainty associated with both predictions and observations suggests a different comparison. The uncertainty on the observations ranges from $18 \%$ to $46 \%$; higher uncertainty is associated with measured values close to the limits of detection due to smaller source terms. The uncertainty on the predictions based on uncertainty in the wind file alone ranges from $14 \%$ to $82 \%$ depending upon receptor and year. Uncertainty on the conversion of HT creates a bias in that the predictions should be higher from a tiny fraction to about $4 \%$. No uncertainty seems due to the location of the sampler. Not knowing precise exit velocities from discharge points is unlikely to add more than a few percent to the overall uncertainty on the predictions. The low bias on the observations from rotameter measurements may be approximately offset by the low bias on the predictions from neglecting HT.

The comparison of predictions and observations that takes into account uncertainty on both is clearly an improvement over the deterministic $\mathrm{P} / \mathrm{O}$ ratios. This is seen in Table 4, where the shaded areas indicate when uncertainty on predictions overlaps uncertainty on observations and/or the $\mathrm{P} / \mathrm{O}$ ratio is greater than one. Agreement between predictions and observations occurs in $75 \%$ of the results. In an additional $12 \%$ of the cases, the $\mathrm{P} / \mathrm{O}$ ratio is greater than one without there being agreement between predictions and observations.

\section{DISCUSSION}

Air concentrations are always predicted accurately or over-predicted at COW, SALV, VIS, and ZON7 (Table 4). COW, VIS and ZON7 lie in the directions towards which the wind blows most frequently from all the sources. Over-predictions at these locations could be due to the real plume's undergoing lateral or vertical spreading that is not accounted for in CAP88-PC's treatment of stability. The predicted concentrations at SALV are mostly due to the TRL and CSA. SALV lies to the northeast of SNL. In addition, SALV lies just $270 \mathrm{~m}$ to the southeast of the CSA, 
and, therefore, the diffuse source there has a significant impact at SALV. Notably, in $30 \%$ of these cases, although the uncertainty bounds on predictions and observations do not overlap, the $\mathrm{P} / \mathrm{O}$ ratio is greater than one. The predictions, therefore, cannot be said to agree with the observations.

Uncertainty bounds on predictions and observations overlap for all years except 1992 at POOL (Table 4), although the overlap for 1991, 1993, and 1996 is small, as reflected by the $\mathrm{P} / \mathrm{O}$ ratios for those years. For 1992, the gap between the upper limit of the predictions (with an uncertainty of 55\%) and the lower limit of the observations (with an uncertainty of 19\%) is quite large and is unlikely to be reduced by any further uncertainty to the point that predictions and observations can be considered the same. The TF has more effect on the air concentrations at POOL than does the TRL. The POOL sampler is particularly affected by the Waste Accumulation Area (WAA) adjacent to the TF because the WAA is so close. The WAA contributed $66 \%$ of the predicted HTO concentration in air at POOL in 2000. The tritium sampler at POOL is little affected by changes in exit velocity from the TF. As well, accounting for HT converted to HTO would have an insignificant effect on the results.

The locations that are under-predicted in the earlier years are those to the west, south, and in the hills. Predictions at FIRE and LCCY are normally better matched to the observations than those at MESQ and MET. Although the uncertainty on predictions at MESQ (about 65\%) and MET (about 50\%) accounts for much of the agreement with the observations (Table 4), another explanation needs to be found for the differences seen in 1986, 1987 and 1992. MET and MESQ lie on the perimeter of LLNL site's west boundary (Fig. 1). At both the old and current locations for each sampler, releases from the TF contributed about half or more of the predicted air concentrations prior to the existence of the WAA. Winds blow towards MET or MESQ less than $8 \%$ of the time from the various sources. At LLNL, light winds blow to the west and northwest mainly at night when the stability classes are $\mathrm{E}$ and $\mathrm{F}^{\mathrm{tt}}$. As a result, the highest air concentrations predicted by CAP88-PC come to ground about $3000 \mathrm{~m}$ from a stack source, well beyond MESQ or MET (Fig. 2). Lack of vertical mixing with E and especially F stability class, in CAP88-PC has caused underestimation closer to the source.

CAFÉ and VET are two locations to the south of LLNL whose air concentrations are under-predicted by CAP88-PC during the first few years, although the overall agreement looks much better when uncertainties are compared. Uncertainties on predictions at both locations are high (60\% and $45 \%$ respectively), but not sufficient in 1986 and 1987 to cause agreement between predictions and observations (with about 18\% uncertainty). Locations close to elevated sources but not in the direction of the prevailing winds, such as CAFÉ, usually have higher air concentrations than predicted by CAP88-PC. A Gaussian plume model is very sensitive to the vertical dispersion parameter $\left(\square_{z}\right)$ close in, so if $\square_{z}$ is not specified correctly, the predictions will be incorrect. Furthermore, given that winds blow

\footnotetext{
† Bowen, B. Personal communication.
} 
towards the south mostly during daytime, tritium releases from facilities usually occurred during work hours, and the wind file for CAP88 is based on 24-hour winds, higher concentrations are expected towards the south than could be predicted by the model. This may be the explanation for under-predictions at VET for the years the primary source of air tritium came from stack releases.

Prior to 1991, CAP88-PC's success rate is poor at the locations in the hills (XRDS and ALTA). The uncertainty on the predictions is not very large (30\% for XRDS and 18\% for ALTA, which is comparable to the uncertainty on the observations). Air concentrations may be underestimated by CAP88-PC because it is a model for flat terrain. However, because streamlines tend to follow the terrain, except for changes in wind direction induced by the hills, the hills might not even be there, from the atmosphere's point of view. Although ALTA and AMON are farther from the sources than is either XRDS_X or XRDS_C, the fact that they lie more in the direction towards which the prevailing wind blows may explain why the comparison of predictions and observations is similar at the two sets of locations.

In 1993 and later, all predictions for all locations either have overlapping uncertainty bounds or exceed the observed concentrations (Table 4). These results are very different from the early years $(1986-1992)$, especially if $\mathrm{P} / \mathrm{O}$ ratios are compared. Although nearly all predictions for both sets of data fall within a factor of three of the observations (Table 5), the fraction of $\mathrm{P} / \mathrm{O}$ ratios greater than one for 1993 and later is nearly twice that of the early years. This difference seems caused by the existence of the WAA, which was relatively significant for the first time in 1993. The WAA contributes more to air concentrations to the west and the south, locations that are noticeably underestimated by CAP88-PC in earlier years.

The CSA also contributes significantly to some sampling locations. The effect was particularly noticeable for samplers CAFÉ, MESQ, MET, SALV, and, to a lesser extent, VIS and VET as well. In 1990, when the CSA contributed just 1.5\% of the total tritium released, $38 \%$ of the total predicted tritium at CAFÉ was contributed by the CSA; this percentage is the highest of any of the years at any location. Thus, the presence of diffuse sources seems to have a great effect on whether or not predictions match or exceed measured air concentrations. Without this contribution from the CSA between 1986 and 1992, it is likely that many more predictions would have been different from the observations. With few exceptions, dilution factors for the diffuse sources are very large compared with those for stack sources for all sampling locations.

In 1998 and later, the fraction of tritium from diffuse sources has been over $5 \%$, which is much higher than earlier. The high percentage of deterministic overprediction for 1998 onwards is probably due to the high fraction of tritium from diffuse sources coupled with the relatively high dilution factors for diffuse sources. For samplers very close to a source, a small diffuse source can easily contribute more to the local air concentration than a much larger elevated source. 
It is not clear why such relatively poor agreement between predictions and observations occurs in 1986, 1987, and 1992 (Table 4). One might suspect a missing diffuse source, but because most operations last longer than a year, this is not a likely explanation. As well as looking for missing sources for years when CAP88-PC under-predicted air concentrations, one might also wonder if some published release rates might have been higher than what was actually released to explain the high predictions, on average, in 1989. Even when contributions from the CSA and the TRL in 1989 are ignored, predicted air concentrations at $58 \%$ of the sampling locations are higher than the observations.

The average uncertainty on the observations in 1986 was $18 \%$, and it increased gradually to $33 \%$ by 2001 due to the increase in analytical uncertainty, as the concentrations got closer to the detection limits. The uncertainty on predictions varied by location according to which sources were active during a year. On average, the uncertainty was the least (25\%) for locations to the northeast and the most $(60 \%)$ for locations to the west. Even had it not been for the apparent effect of the diffuse sources after 1993 resulting in deterministic over-predictions, agreement between predictions and observations might have been expected to be relatively good, given the increased chance of overlap due to higher uncertainty on the observations.

It is unlikely that any deficiencies in results can be explained by the improper location of older sampling stations.

\section{CONCLUSIONS}

Air concentrations predicted by CAP88-PC at LLNL are very sensitive to diffuse sources. A very small release from a diffuse source can contribute a large fraction of the air concentration at locations such as CAFÉ, MESQ, MET, and POOL that are near diffuse sources. The contribution from the WAA from 1993 on probably accounts for the agreement between predictions and observations seen between 1993 and 2001. Before 1993

- CAP88-PC generally overestimated (even to the point where predictions and observations did not match) annual average air concentrations in the direction towards which the prevailing winds blow.

- Predicted air concentrations at locations towards the west were quite consistently lower than observed, and even high uncertainty could not account for some differences between predictions and observations.

- Locations close to elevated sources but not in the direction of the prevailing winds, such as CAFÉ, usually had higher air concentrations than predicted by CAP88-PC. Furthermore, higher concentrations are observed towards the south than could be predicted by the model (for example, at VET). Again, even high uncertainty could not account for some differences between predictions and observations.

- Air concentrations in the hills were underestimated by CAP88-PC. 
Although observations were improved by the removal of obviously improbable concentrations, still other observations may be suspect. The time for preparing a good data set of observations is while the observations are being collected, not years after the fact. The quality of observations for monitoring purposes can be very different from the quality needed to test models (Peterson and Kirchner 1998). Monitoring data are often accepted because they are well below any level of concern, although they actually may not be accurate. For model testing, the accuracy of the values is vital. As well, concentrations near or below the lower limit of detection are not suitable for testing models. For this test, uncertainties from silica gel correction, variation in flow rate, analytical error, and uncertainty associated with subtracting background tritium levels were taken into account. Although the exact uncertainty due to correcting for the latent water in silica gel is unknown, this approach represents a reasonably accurate assessment of uncertainty on the observations, but only if the observation was representative in the first place.

Uncertainty on the predictions was harder to quantify. The uncertainty that arose because of the use of the 5-year average wind file was calculated, and the uncertainty based on potential variability in the exit velocities was estimated. It is likely that analytical error on molecular sieve samplers (TF) or bubblers (TRL) was quite low during the early years because tritium concentrations would have been high, so analytical uncertainty is probably not a significant contributor to overall uncertainty on predictions at a time when this would have affected the results (in recent years with lower release rates, the uncertainty on the samples is greater, but the predictions and observations may be considered the same (Table 4)). The contribution to the measured HTO from HT releases was ignored, because CAP88PC cannot account for HT releases. In addition, the tiny increase to the predictions would have no effect on the results of the model test. Finally, with the possible exception of locations MESQ_X and MET_X, the locations of sources and receptors introduced essentially no uncertainty because the locations were known accurately using GPS.

Obviously, not all uncertainty can be accounted for quantitatively and accurately. If uncertainty had been greater for this test of CAP88-PC, there would be more overlap of predictions and observations and the model might appear to be better, because more predictions would match the observations. Some of the uncertainties in this test were quite large $\mathrm{e}^{\S \S}$, and in other model tests, uncertainties might be so great that the test could turn out to be meaningless. By analyzing the uncertainty on observations and predictions, not only is the confidence in predictions and observations assessed but the significant differences that require explanation are clarified.

The overall uncertainty on the CAP88-PC dispersion model, or any model, is obtained from various tests. The results of this test using LLNL monitoring data are

$\$$ At location MET in 1994, the uncertainty was $34 \%$ on the observations and $71 \%$ on the predictions. 
similar to other tests of CAP88-PC. A comparison of AIRDOS-EPA predictions of air concentrations for various radionuclides ${ }^{234} \mathrm{U},{ }^{238} \mathrm{U},{ }^{85} \mathrm{Kr}$, and $\left.{ }^{3} \mathrm{H}\right)$ with measurements at six different sites (Jack Faucett Associates, Inc. and SC \& A, Inc. 1987), over distances ranging from $180 \mathrm{~m}$ to $27.7 \mathrm{~km}$, concluded that the $90 \%$ confidence interval for the accuracy of the CAP88-PC dispersion model ranges from a factor of 0.3 to 4.4 (based on 51 samples). The results of this test with LLNL data appear to support the Faucett Associates' earlier testing, given that the bulk of CAP88-PC's predictions fell within a factor of 0.33 to 3 and only 8 out of 159 results fell below 0.3 .

Using HTO monitoring data collected with silica gel, a study at the Savannah River Site compared P/O ratios for three dispersion models (AXAIRQ, MAXIGASP, and CAP88-PC) for annual average air tritium concentrations at 13 locations from 1985 through 1994. The locations were offsite and ranged in distance from 8600 to nearly $18000 \mathrm{~m}$ from the source. All three models consistently overestimated the observed concentrations. CAP88-PC's ten year average $\mathrm{P} / \mathrm{O}$ ratio was $1.4 \pm 0.39^{\ddagger \ddagger}$ (Simpkins and Hamby 1997). The measured concentrations in extracted water were multiplied by the absolute humidity to obtain air concentrations in $\mathrm{Bq} / \mathrm{m}^{3}$. No corrections were made for latent water in the silica gel because this study took place before this feature of silica gel was known. Depending upon the relationship between dry silica gel weight and adsorbed water from the air, correcting for latent water would probably lower the 10-year average $\mathrm{P} / \mathrm{O}$ ratio and would distribute the $\mathrm{P} / \mathrm{O}$ ratios quite evenly above and below 1.0 , which is more in accordance with what has been seen elsewhere.

CAP88-PC was tested in the Tritium Working Group of the International Atomic Energy Agency's BIOMASS (BIOspheric Modelling and ASSessment) Coordinated Research Programme (IAEA 2003). The dispersion equations in CAP88-PC were used to calculate air concentrations at four locations from three tritium sources at Valduc, a research establishment of the Commissariat à l'Energie Atomique in France. The distances from source to receptor ranged from 3500 to $6800 \mathrm{~m}$. P/O ratios were calculated for 38 mean annual air concentrations. CAP88-PC's predictions were similar to those of the other five models participating. The distribution of $\mathrm{P} / \mathrm{O}$ ratios for the Valduc data was analyzed similarly to Table 5. All results fell within a factor of 3 , which again does not show quite as much overestimation as in the Faucett study. The fraction (0.37) of $\mathrm{P} / \mathrm{O}$ ratios greater than 1.0 was low, but it is the same as that for offsite locations from LLNL (Table 5).

The deterministic results from testing CAP88-PC with several different data sets indicate that CAP88-PC performs as well as any simple dispersion model over flat terrain, with predictions fairly evenly distributed above and below a factor of three. (Ninety-six percent of all predictions fall within a factor of three of the observations, and the fraction of predicted air concentrations greater than the observed air concentrations is 0.54.) This is a good result, showing neither bias nor extreme under or over-predictions. For this test, outliers were removed from the observations, an attempt was made to include all possible sources of released tritium,

\footnotetext{
For comparison, in this study, the average $\mathrm{P} / \mathrm{O}$ ratio was $1.1 \pm 0.58$.
} 
and predicted air concentrations were weighted for the position of the receptor in the sector. However, even without such efforts to improve CAP88-PC's predicted air concentrations, the overall results are respectable. Ninety-four percent of these unimproved predictions fall within a factor of three of the unimproved observations, and the fraction of predictions that is higher than the observed air concentrations is 0.46. This is reassuring because data for normal use of CAP88-PC and NESHAPs compliance are "unimproved".

The deterministic results may not be as good as what might be expected from a regulatory model, however, particularly since several parameters in CAP88-PC were chosen so that air concentrations would be conservative. The results of testing CAP88-PC while accounting for uncertainties in the observations and predictions reveal that $75 \%$ of the predictions may be considered the same as the observations. There are also nineteen instances when CAP88-PC over-predicts the observations but, at the same time, the uncertainties on the predictions and observations fail to overlap (Table 4). Given that it is desirable for CAP88-PC to over-predict rather than under-predict, and given that the over-predictions are only high by an average factor of 2.2, it seems reasonable that these over-predictions be included in the final fraction of successful results. Doing this, CAP88-PC's predictions are the same as or exceed (by at most a factor of 3.3) the observations at LLNL $87 \%$ of the time. By accounting for uncertainties, CAP88-PC's performance is shown to be better or more acceptable for a regulatory model than is the case when only $\mathrm{P} / \mathrm{O}$ ratios are compared. 


\section{REFERENCES}

Bunnenberg C, Feinhals J, Wiener B. Differences in the behavior of $\mathrm{HTO}$ and $\mathrm{H} 2 \mathrm{O}$ in soil after condensation from the atmosphere and conversion of HT to HTO and OBT in soil relative to moisture content and pore volume. Rad Prot Dos 14: 83-87; 1986.

Davis PA, Bickel GA. Environmental HTO / HT ratios arising from a chronic atmospheric HT release. In: Proceedings of the International Workshop on the Environmental Behavior of Tritium, Osaka, Japan; 2000.

Guthrie E, Bandong B, Shen N. Isotope exchange and fractionation corrections for extraction of tritiated water in silica gel by freeze-drying techniques. Lawrence Livermore National Laboratory, Livermore, CA. UCRL-ID-148610; June 2002.

Harrach RJ, Peterson S-R, Gallegos GM, Tate PJ, Bertoldo NA, Althouse PE. LLNL NESHAPs 2001 Annual Report. Lawrence Livermore National Laboratory, Livermore, CA. UCRL-ID-113867-02; 2002.

Holland RC, Buddemeier RW, Brekke DD. Environmental monitoring at the Lawrence Livermore National Laboratory. 1986 Report. Environmental Protection Guidance and Monitoring Series. Lawrence Livermore National Laboratory, Livermore, CA. UCRL-50027-86; April 1987.

Holland RC, Brekke DD. Environmental monitoring at the Lawrence Livermore National Laboratory. 1987 Report. Environmental Protection Guidance and Monitoring Series. Lawrence Livermore National Laboratory, Livermore, CA. UCRL-50027-87; April 1988.

International Atomic Energy Agency. Modelling the environmental transport of tritium in the vicinity of long term atmospheric and sub-surface sources. Report of the Tritium Working Group of the Biosphere Modelling and Assessment (BIOMASS) Programme, Theme 3. IAEA, Vienna. IAEABIOMASS-3. March 2003.

International Atomic Energy Agency/World Health Organization. IAEA/WHO Global Network of Isotopes in Precipitation; 2001. The GNIP Database Available at http:/ / isohis.iaea.org.

Jack Faucett Associates Inc. and SC\&A, Inc. Comparison of AIRDOS-EPA predictions of ground-level airborne radionuclide concentrations to measured values. Jack Faucett Associates, Bethesda, MD. 20814; JACKFAU-341/12-87; 1987.

Miller CW, Hively LM. A review of validation studies for the Gaussian plume atmospheric dispersion model. Nuclear Safety 28:523-531; 1987. 
Parks BS. User's Guide for CAP88-PC, Version 1.0. Washington, DC: U.S. Environmental Protection Agency 402-B-92-001; 1992.

Parks BS. CAP88-PC Version 2.0 User's Guide. Germantown, MD: U.S. Department of Energy ER-8/GTN; 1997.

Peterson, S-R, Kirchner TB. Data quality and validation of radiological assessment models. Health Phys 74:147-157; 1998.

Simpkins AA, Hamby DM. Predicted versus measured tritium oxide concentrations at the Savannah River Site. Health Phys 72:179-185; 1997.

U.S. Environmental Protection Agency. Code of Federal Regulations. Washington, DC: U.S. Government Printing Office; 40 CFR Part 61: 1989. 


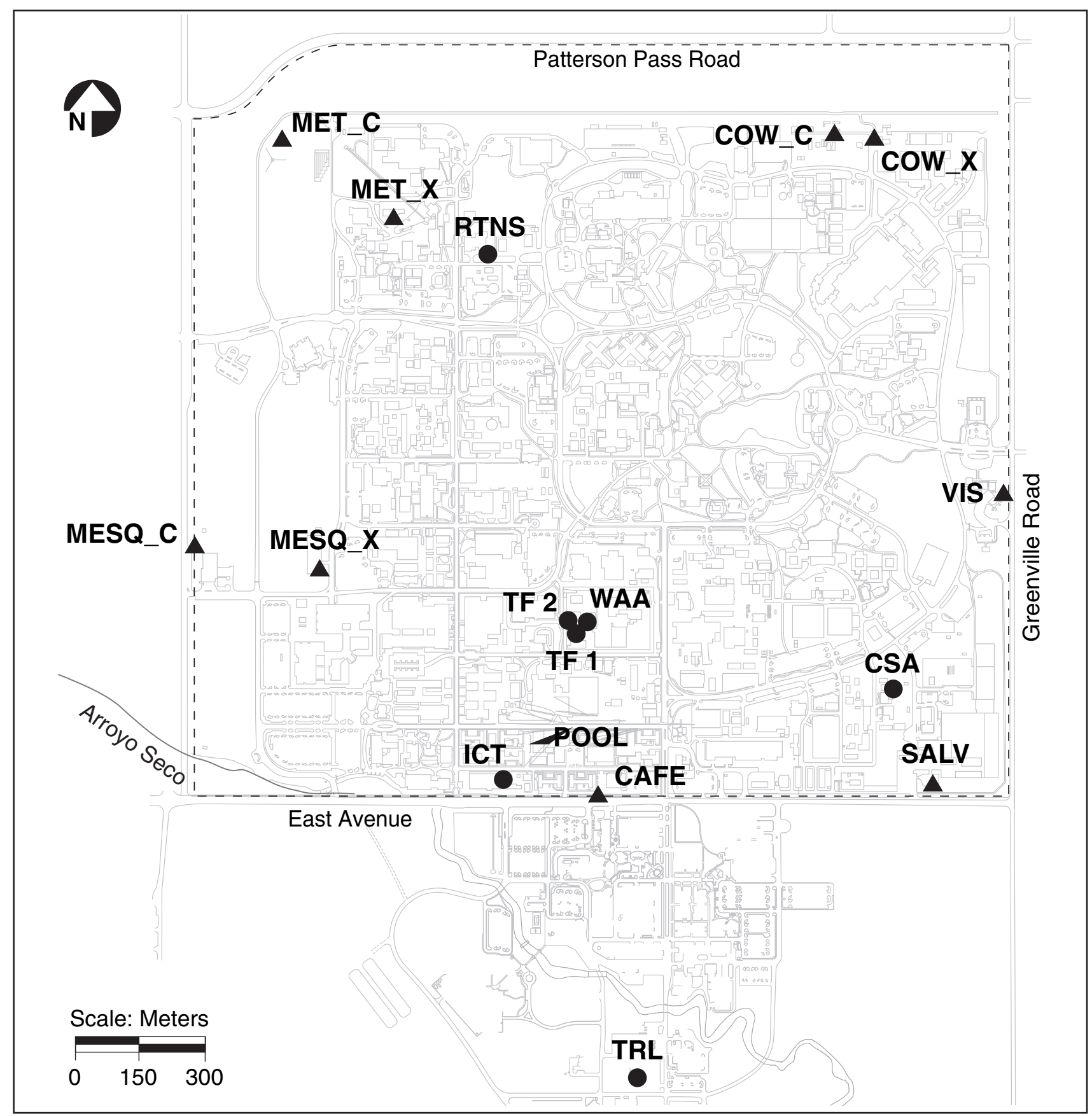

Figure 1. Locations of sources and perimeter air tritium samplers at LLNL. Old locations for samplers are indicated SAMP_X; current locations are indicated SAMP_C. Samplers that have stayed in one place for 1986-2001 are simply indicated as SAMP. Locations of air

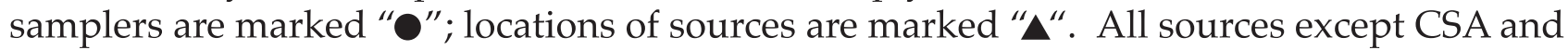
WAA are stack. 


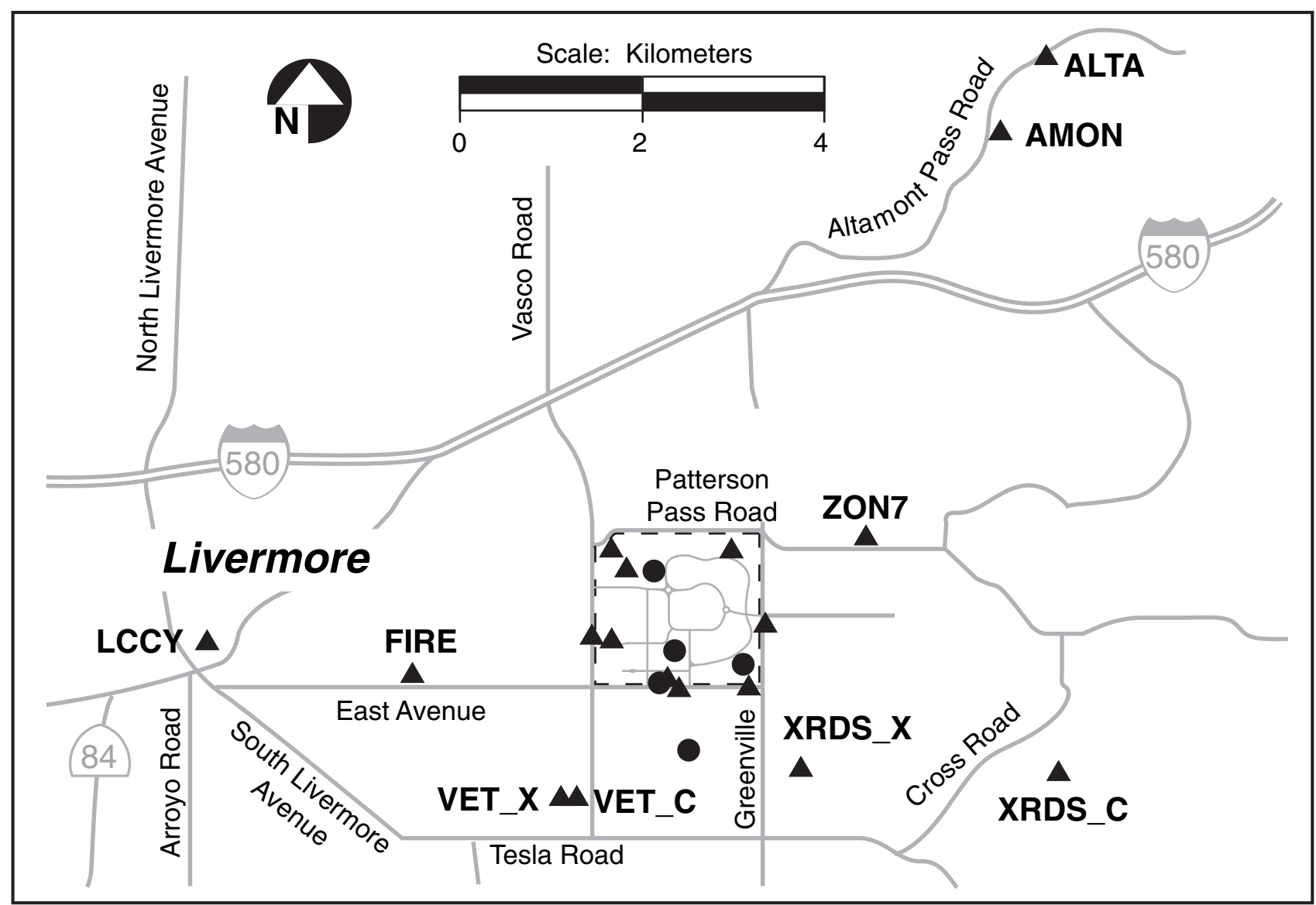

Figure 2. Locations of sources and offsite air tritium samplers in the Livermore Valley. Old locations for samplers are indicated SAMP_X; current locations are indicated SAMP_C (AMON is the current location replacing ALTA). Samplers that have stayed in one place for 1986-2001 are simply indicated as SAMP. Locations of air samplers are marked " $\mathbf{\Lambda}$ "; locations of sources are marked "O". 
Table 1a. Observed mean annual air concentrations $\left(\mathrm{pCi} \mathrm{m}^{-3}\right)$ at onsite locations (Fig. 1). Values are corrected for latent water in silica gel with tritium background subtracted \pm uncertainty arising from analytical, silica gel correction, variation in flow rate, and tritium background uncertainties for seven locations. Current sampling locations are indicated either as "SAMP" or "SAMP_C"; old locations are indicated as "SAMP_X".

\begin{tabular}{|c|c|c|c|c|c|c|c|c|c|c|c|c|c|c|c|c|c|c|c|c|c|}
\hline \multicolumn{2}{|l|}{ Location } & \multicolumn{2}{|c|}{ CAFÉ } & \multicolumn{3}{|c|}{$\begin{array}{c}\text { COW_X } \\
\left({ }^{\prime} 86-' 99\right) \\
\text { COW_C ('99-) }\end{array}$} & \multicolumn{3}{|c|}{$\begin{array}{c}\text { MESQ_X } \\
(' 86-' 88) \\
\text { MESQ_C ('89 -) }\end{array}$} & \multicolumn{3}{|c|}{$\begin{array}{c}\text { MET_X } \\
\left({ }^{\prime} 86-' 88\right) \\
\text { MET_C ('89-) }\end{array}$} & \multicolumn{3}{|c|}{ POOL } & \multicolumn{3}{|c|}{ SALV } & \multicolumn{3}{|c|}{ VIS } \\
\hline 1986 & 58 & \pm & 10 & 39 & \pm & 7.1 & 48 & \pm & 8.8 & 54 & \pm & 9.8 & & & & 81 & \pm & 15 & 47 & \pm & 8.5 \\
\hline 1987 & 92 & \pm & 16 & 45 & \pm & 8.3 & 19 & \pm & 9.0 & 37 & \pm & 6.8 & & & & 60 & \pm & 11 & 86 & \pm & 16 \\
\hline 1988 & 94 & \pm & 17 & 42 & \pm & 7.7 & 43 & \pm & 7.8 & 28 & \pm & 5.3 & & & & 49 & \pm & 8.8 & 67 & \pm & 12 \\
\hline 1989 & 50 & \pm & 9.2 & 30 & \pm & 5.8 & 35 & \pm & 6.7 & 13 & \pm & 2.6 & & & & 25 & \pm & 4.8 & 48 & \pm & 8.6 \\
\hline 1990 & 29 & \pm & 5.4 & 16 & \pm & 3.0 & 17 & \pm & 3.1 & 11 & \pm & 2.2 & & & & 23 & \pm & 4.4 & 28 & \pm & 5.1 \\
\hline 1991 & 31 & \pm & 5.6 & 17 & \pm & 3.2 & 19 & \pm & 3.7 & 14 & \pm & 3.8 & 47 & \pm & 8.5 & 9.5 & \pm & 1.8 & 20 & \pm & 3.8 \\
\hline 1992 & 8.8 & \pm & 1.7 & 4.4 & \pm & 0.95 & 6.9 & \pm & 0.97 & 4.1 & \pm & 0.89 & 15 & \pm & 2.8 & 6.1 & \pm & 1.3 & 7.0 & \pm & 1.4 \\
\hline 1993 & 8.3 & \pm & 1.6 & 4.8 & \pm & 1.0 & 4.5 & \pm & 0.57 & 2.9 & \pm & 0.72 & 14 & \pm & 2.7 & 5.9 & \pm & 1.2 & 6.6 & \pm & 1.3 \\
\hline 1994 & 3.5 & \pm & 0.80 & 2.3 & \pm & 0.64 & 2.1 & \pm & 0.50 & 1.5 & \pm & 0.54 & 5.7 & \pm & 1.2 & 5.5 & \pm & 1.1 & 3.9 & \pm & 0.88 \\
\hline 1995 & 5.4 & \pm & 1.1 & 2.7 & \pm & 0.67 & 1.6 & \pm & 0.71 & 2.1 & \pm & 0.58 & 9.3 & \pm & 1.8 & 5.0 & \pm & 1.0 & 3.9 & \pm & 0.88 \\
\hline 1996 & 8.3 & \pm & 1.6 & 5.8 & \pm & 1.2 & 2.9 & \pm & 0.54 & 2.1 & \pm & 0.59 & 14 & \pm & 2.6 & 3.6 & \pm & 0.83 & 7.8 & \pm & 1.6 \\
\hline 1997 & 6.2 & \pm & 1.2 & 5.6 & \pm & 1.1 & 1.7 & \pm & 0.56 & 1.3 & \pm & 0.52 & 14 & \pm & 2.6 & 2.2 & \pm & 0.64 & 10 & \pm & 2.0 \\
\hline 1998 & 4.5 & \pm & 0.98 & 2.5 & \pm & 0.63 & 1.4 & \pm & 0.63 & 1.2 & \pm & 0.48 & 10 & \pm & 1.9 & 4.4 & \pm & 0.95 & 3.6 & \pm & 0.84 \\
\hline 1999 & 9.3 & \pm & 1.8 & 5.8 & \pm & 1.2 & 3.6 & \pm & 0.84 & 2.7 & \pm & 0.65 & 12 & \pm & 2.3 & 1.2 & \pm & 0.48 & 5.9 & \pm & 1.2 \\
\hline 2000 & 1.9 & \pm & 0.55 & 1.5 & \pm & 0.55 & & & & & & & 4.5 & \pm & 0.97 & & & & 2.4 & \pm & 0.68 \\
\hline 2001 & 1.2 & \pm & 0.48 & & & & & & & & & & 2.5 & \pm & 0.61 & & & & 1.4 & \pm & 0.55 \\
\hline
\end{tabular}




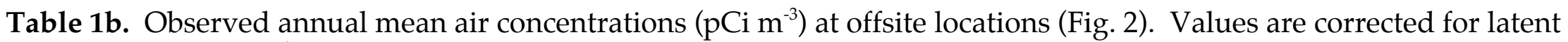
water in silica gel with tritium background subtracted \pm uncertainty arising from analytical, silica gel correction, variation in flow rate, and tritium background uncertainties for six locations. Current sampling locations are indicated either as "SAMP" or "SAMP_C"; old locations are indicated as "SAMP_X". Estimated mean air tritium concentrations and uncertainty from fallout and cosmogenic sources of tritium are shown in the last column.

\begin{tabular}{|c|c|c|c|c|c|c|c|c|c|c|c|c|c|c|c|c|c|c|c|}
\hline \multirow{2}{*}{$\begin{array}{c}\text { Location } \\
1986\end{array}$} & \multicolumn{2}{|c|}{$\begin{array}{c}\text { ALTA } \\
\text { ('86-'97) }\end{array}$} & \multicolumn{3}{|c|}{ FIRE } & \multicolumn{3}{|c|}{ LCCY } & \multicolumn{3}{|c|}{$\begin{array}{c}\text { VET_X } \\
\left({ }^{\prime} 86-{ }^{\prime} 96\right) \\
\text { VET_C ('97-) }\end{array}$} & \multicolumn{2}{|c|}{$\begin{array}{c}\text { XRDS_X } \\
\left({ }^{\prime} 86-' 87\right) \\
\text { XRDS_C ('88 -) }\end{array}$} & \multicolumn{3}{|c|}{ ZON7 } & \multicolumn{3}{|c|}{$\begin{array}{l}\text { Livermore } \\
\text { Background }\end{array}$} \\
\hline & 16 & \pm 3.1 & 17 & \pm & 3.3 & & & & & & & $32 \pm$ & 5.8 & 24 & \pm & 4.5 & 0.14 & \pm & 0.095 \\
\hline 1987 & 29 & \pm 5.3 & 23 & \pm & 4.3 & 27 & \pm & 5.0 & 37 & \pm & 6.8 & $51 \pm$ & 9.2 & 38 & \pm & 7.0 & 0.15 & \pm & 0.12 \\
\hline 1988 & 20 & \pm 3.7 & 20 & \pm & 4.1 & 18 & \pm & 3.5 & 33 & \pm & 6.1 & $26 \pm$ & 5.2 & 33 & \pm & 6.1 & 0.11 & \pm & 0.074 \\
\hline 1989 & 8.6 & \pm 1.8 & 11 & \pm & 2.3 & 6.3 & \pm & 1.4 & 23 & \pm & 4.3 & $13 \pm$ & 2.8 & 22 & \pm & 4.2 & 0.11 & \pm & 0.090 \\
\hline 1990 & 7.1 & \pm 1.6 & 6.5 & \pm & 1.5 & 4.6 & \pm & 1.1 & 11 & \pm & 2.2 & $7.5 \pm$ & 1.7 & 14 & \pm & 2.7 & 0.096 & \pm & 0.087 \\
\hline 1991 & 5.6 & \pm 1.3 & 6.7 & \pm & 1.5 & 5.5 & \pm & 1.3 & 13 & \pm & 3.5 & $5.7 \pm$ & 1.4 & 9.2 & \pm & 1.9 & 0.11 & \pm & 0.080 \\
\hline 1992 & 1.7 & \pm 0.56 & 2.2 & \pm & 0.62 & 1.7 & \pm & 0.55 & 4.0 & \pm & 0.87 & $2.8 \pm$ & 0.68 & 4.0 & \pm & 0.87 & 0.080 & \pm & 0.060 \\
\hline 1993 & 1.2 & \pm 0.44 & 1.5 & \pm & 0.53 & 0.98 & \pm & 0.44 & 3.3 & \pm & 0.76 & $2.0 \pm$ & 0.56 & 3.0 & \pm & 0.73 & 0.085 & \pm & 0.077 \\
\hline 1994 & & & & & & & & & 1.9 & \pm & 0.59 & $1.1 \pm$ & 0.49 & 2.0 & & 0.55 & 0.083 & \pm & 0.059 \\
\hline 1995 & & & & & & & & & 2.0 & \pm & 0.56 & & & 1.0 & & 0.45 & 0.092 & \pm & 0.065 \\
\hline 1996 & 0.93 & \pm 0.42 & & & & & & & 1.7 & \pm & 0.53 & & & 2.8 & & 0.69 & 0.088 & \pm & 0.068 \\
\hline 1997 & & & & & & & & & 1.1 & \pm & 0.77 & & & 2.8 & & 0.69 & 0.079 & \pm & 0.056 \\
\hline 1998 & & & & & & & & & & & & & & 1.1 & \pm & 0.47 & 0.097 & \pm & 0.094 \\
\hline 1999 & 1.5 & \pm 0.49 & & & & & & & & & & & & 2.8 & \pm & 0.68 & 0.083 & \pm & 0.062 \\
\hline 2000 & & & & & & & & & & & & & & & & & 0.072 & \pm & 0.051 \\
\hline 2001 & & & & & & & & & & & & & & & & & 0.072 & \pm & 0.065 \\
\hline
\end{tabular}


Table 2. Source terms for LLNL ${ }^{a}$ and SNL $\left(\mathrm{Ci} \mathrm{HTO}^{-1}\right)$.

\begin{tabular}{|c|c|c|c|c|c|c|c|}
\hline \multirow[b]{2}{*}{ Year } & \multicolumn{2}{|c|}{$\begin{array}{l}\text { Tritium Facility } \\
\text { (TF) }\end{array}$} & \multirow{2}{*}{$\begin{array}{l}\text { Container } \\
\text { Storage Area } \\
\text { (CSA); diffuse }\end{array}$} & \multirow{2}{*}{$\begin{array}{c}\text { Waste } \\
\text { Accumulation } \\
\text { Area (WAA); } \\
\text { diffuse }\end{array}$} & \multirow{2}{*}{$\begin{array}{l}\text { Rotating Target } \\
\text { Neutron Source } \\
\text { (RTNS); stack }\end{array}$} & \multirow{2}{*}{$\begin{array}{c}\text { Insulating Core } \\
\text { Accelerator } \\
\text { (ICT); stack }\end{array}$} & \multirow{2}{*}{$\begin{array}{l}\text { SNL Tritium } \\
\text { Research } \\
\text { Laboratory } \\
\text { (TRL); stack }\end{array}$} \\
\hline & Stack 1 & Stack 2 & & & & & \\
\hline 1986 & 239 & 422 & 13.2 & & 106 & 2.01 & 615 \\
\hline 1987 & 603 & 644 & 24.9 & & 78.5 & 3.70 & 573 \\
\hline 1988 & 542 & 1094 & 32.7 & & 5.29 & & 1035 \\
\hline 1989 & 860 & 695 & 35 & & 2.40 & & 659 \\
\hline 1990 & 333 & 361 & 13.7 & & & & 221 \\
\hline 1991 & 231 & 480 & 14.2 & & & & 351 \\
\hline 1992 & 54.2 & 52.7 & 2.14 & 0.80 & & & 134 \\
\hline 1993 & 41.8 & 73.5 & 2.2 & 3.0 & & & 132 \\
\hline 1994 & 22.4 & 53.8 & 1.2 & 3.0 & & & 91.2 \\
\hline 1995 & 5.95 & 55.9 & 2.1 & 4.0 & & & 73.0 \\
\hline 1996 & 11.3 & 163 & 3.0 & 3.0 & & & \\
\hline 1997 & 10.1 & 257 & 4.2 & 2.5 & & & \\
\hline 1998 & 9.80 & 75.3 & 4.6 & 6.0 & & & \\
\hline 1999 & 5.45 & 208 & 4.4 & 7.3 & & & \\
\hline 2000 & 4.10 & 31.3 & 3.6 & 5.2 & & & \\
\hline 2001 & 2.40 & 15.9 & 2.0 & 1.0 & & & \\
\hline
\end{tabular}

${ }^{a}$ Other published source terms have been ignored for the model testing because their contribution was negligible; by far the largest of these sources was $0.02 \mathrm{Ci} \mathrm{y}^{-1}$.

${ }^{\mathrm{b}} \mathrm{Ci}^{-1}$ for 1986 through 1992 were unpublished but were estimated as 2\% of annual HTO releases from B331. 
Table 3. Stack or source heights, stack diameters or areas of sources, and exit velocities for LLNL and SNL tritium sources.

\begin{tabular}{lcccc}
\hline LLNL & Stack height $(\mathrm{m})$ & \multicolumn{2}{c}{ Stack diameter $(\mathrm{m})$} & \multicolumn{2}{c}{ Exit velocity $\left(\mathrm{m} \mathrm{s}^{-1}\right)$} \\
\hline & & & $1986:$ & 6.39 \\
TF Stack1 & 30 & 1.22 & $1987,1988:$ & 6.92 \\
& & & $1989:$ & 6.78 \\
& & & 1990 on: & 7.59 \\
& & & $1986:$ & 9.72 \\
TF Stack 2 & 30 & 1.22 & $1987,1988:$ & 9.86 \\
& & & $1989:$ & 9.56 \\
RTNS Stack & 18.5 & 0.71 & 1990 on: & 10.5 \\
ICT Stack & 4.27 & 0.5 & 16.8 & 0.5 \\
& Release height $(\mathrm{m})$ & Area of source $\left(\mathrm{m}^{2}\right)$ & Exit velocity $\left(\mathrm{m} \mathrm{s}^{-1}\right)$ \\
CSA & 1.0 & 600 & 0.4 & \\
WAA & 1.0 & 1.0 & \multicolumn{2}{c}{0.5} \\
\hline SNL & Stack height $(\mathrm{m})$ & Stack diameter $(\mathrm{m})$ & Exit velocity $\left(\mathrm{m} \mathrm{s}^{-1}\right)$ \\
\hline TRL & 30 & 1.0 & \multicolumn{2}{c}{27.6}
\end{tabular}


Table 4. Predicted to observed ratios for all locations and all years. Shaded cells indicate either when the uncertainty on predictions overlaps with uncertainty on observations or when the $\mathrm{P} / \mathrm{O}$ ratio is greater than one. When the $\mathrm{P} / \mathrm{O}$ ratio is greater than one but the uncertainty bounds of the observations and predictions do not overlap, the value of the ratio is underlined. An $\mathrm{X}$ indicates that data were collected but did not meet the criteria for use in model testing.

\begin{tabular}{|c|c|c|c|c|c|c|c|c|c|c|c|c|c|c|}
\hline Year & $\begin{array}{c}\text { ALTA or } \\
\text { AMON }\end{array}$ & CAFÉ & COW & FIRE & LCCY & MESQ & MET & POOL & SALV & VET & VIS & XRDS & ZON7 & Mean \\
\hline 1986 & 0.38 & 0.49 & 1.1 & 0.59 & $\mathrm{X}$ & 0.29 & 0.19 & & $\mathrm{X}$ & $X$ & 1.2 & 0.43 & 0.95 & 0.63 \\
\hline 1987 & 0.31 & 0.50 & 1.5 & 0.70 & 0.41 & 0.40 & 0.45 & & 0.91 & 0.48 & 1.0 & 0.32 & 0.85 & 0.65 \\
\hline 1988 & 0.61 & 0.61 & $\underline{2.0}$ & 1.0 & 0.74 & 0.52 & 0.78 & & 1.8 & 0.69 & 1.8 & 0.54 & 1.4 & 1.0 \\
\hline 1989 & 1.2 & 1.1 & $\underline{2.6}$ & 1.7 & 2.1 & 0.67 & 1.0 & & 1.4 & 0.67 & 1.7 & 0.52 & 1.2 & 1.3 \\
\hline 1990 & 0.62 & 0.76 & 2.1 & 1.2 & 1.2 & 0.59 & 0.73 & & 1.4 & 0.83 & 1.7 & 0.62 & 1.1 & 1.1 \\
\hline 1991 & 0.85 & 0.77 & $\underline{2.1}$ & 1.1 & 0.98 & 0.49 & 0.57 & 0.59 & 1.8 & 0.71 & 2.4 & 0.94 & $\underline{1.9}$ & 1.2 \\
\hline 1992 & 0.56 & 0.54 & 1.4 & 0.67 & 0.59 & 0.31 & 0.38 & 0.39 & 1.1 & 0.48 & 1.4 & 0.49 & 1.0 & 0.72 \\
\hline 1993 & 0.85 & 0.68 & 1.4 & 1.1 & 1.1 & 0.64 & 0.63 & 0.57 & 1.8 & 0.61 & 1.6 & 0.69 & 1.4 & 1.0 \\
\hline 1994 & $X$ & 1.1 & $\underline{2.0}$ & $X$ & $\mathrm{X}$ & 1.1 & 0.87 & 1.1 & 1.2 & 0.72 & 1.8 & 0.82 & 1.4 & 1.2 \\
\hline 1995 & $X$ & 0.83 & 1.5 & $X$ & & 1.6 & 0.64 & 0.80 & 1.2 & 0.62 & 1.7 & $X$ & $\underline{2.2}$ & 1.2 \\
\hline 1996 & 0.96 & 0.69 & 1.3 & $X$ & & 0.94 & 0.87 & 0.65 & 1.1 & 1.1 & 1.2 & $X$ & 1.1 & 0.99 \\
\hline 1997 & $X$ & 1.2 & $\underline{2.0}$ & $X$ & & 1.9 & 2.0 & 0.80 & $\underline{2.2}$ & 2.3 & 1.4 & $X$ & 1.7 & 1.7 \\
\hline 1998 & $X$ & 1.4 & $\underline{1.8}$ & $X$ & & 2.4 & 1.5 & 1.1 & $\underline{2.5}$ & $X$ & $\underline{2.0}$ & $X$ & $\underline{1.7}$ & 1.8 \\
\hline 1999 & 0.88 & 0.94 & $\underline{1.7}$ & $\mathrm{X}$ & & 1.3 & 1.0 & 1.2 & 1.7 & $X$ & $\underline{2.1}$ & $X$ & 1.4 & 1.4 \\
\hline 2000 & $\mathrm{X}$ & $\underline{2.4}$ & 1.6 & $X$ & & $X$ & $X$ & 1.8 & $\underline{3.3}$ & $\mathrm{X}$ & $\underline{1.8}$ & $\mathrm{X}$ & $X$ & 2.2 \\
\hline 2001 & $X$ & 1.6 & $X$ & $X$ & & $X$ & $X$ & 1.0 & $\mathrm{X}$ & $X$ & 1.6 & & $X$ & 1.4 \\
\hline Mean & 0.72 & 0.98 & 1.7 & 1.0 & 1.0 & 0.94 & 0.83 & 0.92 & 1.7 & 0.84 & 1.6 & 0.60 & 1.4 & $\begin{array}{c}\text { overall } \\
1.1\end{array}$ \\
\hline
\end{tabular}


Table 5. Distributions of $\mathrm{P} / \mathrm{O}$ ratios for different analyses of results. Negative ratios are simply the negative inverse of the $\mathrm{P} / \mathrm{O}$ ratio (i.e., a $\mathrm{P} / \mathrm{O}$ ratio of 0.5 will become -2.0 ). The negative is used to distinguish a $\mathrm{P} / \mathrm{O}$ ratio of less than one from a $\mathrm{P} / \mathrm{O}$ ratio greater than one.

\begin{tabular}{|c|c|c|c|c|c|c|c|c|}
\hline \multirow{2}{*}{$\begin{array}{l}\text { Range of } \mathrm{P} / \mathrm{O} \\
\text { Ratios }\end{array}$} & \multirow{2}{*}{$\begin{array}{c}\text { Analysis } 1 \\
\text { All data }\end{array}$} & \multicolumn{2}{|c|}{ Analysis 2} & \multicolumn{3}{|c|}{ Analysis 3} & \multicolumn{2}{|c|}{ Analysis 4} \\
\hline & & Perimeter & Offsite & Wind to NE & Wind to $\sim \mathrm{S}$ & Wind to $\mathrm{W}$ & $1986-1992$ & $1993-2001$ \\
\hline-5 to -6 & 1 & 1 & & & & 1 & 1 & \\
\hline-4 to -5 & & & & & & & & \\
\hline-3 to -4 & 4 & 2 & 2 & 1 & 1 & 2 & 4 & \\
\hline-2 to -3 & 12 & 6 & 6 & 1 & 6 & 5 & 12 & \\
\hline-1.5 to -2 & 22 & 12 & 10 & 3 & 11 & 8 & 15 & 7 \\
\hline-1 to -1.5 & 34 & 15 & 19 & 7 & 17 & 10 & 19 & 15 \\
\hline 1 to 1.5 & 44 & 29 & 15 & 19 & 15 & 10 & 19 & 25 \\
\hline 1.5 to 2 & 27 & 23 & 4 & 16 & 6 & 5 & 8 & 19 \\
\hline 2 to 3 & 14 & 11 & 3 & 8 & 4 & 2 & 5 & 9 \\
\hline 3 to 4 & 1 & 1 & & & 1 & & & 1 \\
\hline Total & 159 & 100 & 59 & 55 & 61 & 43 & 83 & 76 \\
\hline $\begin{array}{c}\text { Fraction greater } \\
\text { than } 1.0\end{array}$ & 0.54 & 0.64 & 0.37 & 0.78 & 0.43 & 0.40 & 0.39 & 0.71 \\
\hline $\begin{array}{l}\text { Fraction within a } \\
\text { factor of } 2\end{array}$ & 0.80 & 0.79 & 0.81 & 0.82 & 0.80 & 0.77 & 0.73 & 0.87 \\
\hline $\begin{array}{l}\text { Fraction within a } \\
\text { factor of } 3\end{array}$ & 0.96 & 0.96 & 0.97 & 0.98 & 0.97 & 0.93 & 0.94 & 0.99 \\
\hline
\end{tabular}

